\title{
Long-term outcome of simultaneous septal myectomy and anterior mitral leaflet retention plasty in hypertrophic obstructive cardiomyopathy: the Berlin experience
}

\author{
Eva Maria Delmo Walter, Mariano Francisco Javier, Roland Hetzer \\ Cardio Centrum Berlin, Berlin, Germany \\ Correspondence to: Eva Maria Delmo Walter, MD, PhD. Cardio Centrum Berlin, Unter den Linden 21, 10117 Berlin, Germany. \\ Email: eva.delmowalter@gmail.com.
}

Background: Various surgical strategies designed to relieve left ventricular outflow tract obstruction (LVOTO) and correct mitral regurgitation (MR) in hypertrophic obstructive cardiomyopathy (HOCM) have evolved, yet reports on the long-term outcomes of each technique are scarce. We provide an update on over 20 years' experience at our institution in the standardized surgical treatment of HOCM.

Methods: Between April 1986 and April 2014, 320 cases of endomyocardial resection and 305 septal myectomies were performed at our institution. Out of this sample, 57 patients (mean age $38 \pm 2.5$ years, median 16.2, range 3 months-79.8 years) underwent surgery for HOCM involving septal myectomy and anterior leaflet retention plasty (ALRP), intended to obviate the systolic anterior motion (SAM) phenomenon. The preoperative mean LVOT pressure gradient was 98.98 26.2 (median 90, range 60-160) $\mathrm{mmHg}$ with moderate-severe MR. Standard subaortic septal myectomy was performed by resecting long blocks of septal myocardium, continued apically beyond the point of the mitral-septal contact. Through a left atriotomy, the segment of anterior mitral leaflet (AML) closest to the trigones was sutured to the corresponding posterior annulus on both sides. Cardiopulmonary bypass was resumed for repeat septal myectomy if the LVOT pressure gradient was greater than $20 \mathrm{mmHg}$.

Results: Following surgical correction, the mean LVOT pressure gradient was significantly decreased to $12.3 \pm 2.7$ (median 14, 18-25) $\mathrm{mmHg}(\mathrm{P}<0.001)$. Septal thickness was reduced from a preoperative mean of $28.2 \pm 3.4$ (median $30,25-34)$ to $10.5 \pm 1.1(12,15-23) \mathrm{mm}(\mathrm{P}<0.001)$. During a mean follow-up of $17.5 \pm 1.3$ years (median 12, range 1-23.2 years), MR was trivial in $87 \%$ and SAM was non-existent in all, outcomes that were maintained at the latest follow-up. Two patients underwent mitral valve (MV) replacement 1 and 5 years after ALRP for recurrent MR. Two patients eventually underwent heart transplantation for end-stage heart failure, 2 and 11 years later, respectively. Twenty-year freedom from repeat MV intervention and cumulative survival rate was $92.9 \%$ and $91.2 \%$, respectively.

Conclusions: Long-term follow up of HOCM patients who underwent simultaneous septal myectomy and ALRP showed sustained absence of SAM, attenuation of MI, absence of residual LVOT obstruction and sustained improvement in hemodynamic and functional status.

Keywords: Hypertrophic obstructive cardiomyopathy (HOCM); mitral systolic anterior motion (SAM); mitral valve repair

Submitted Aug 25, 2015. Accepted for publication Feb 14, 2017.

doi: $10.21037 /$ acs.2017.03.08

View this article at: http://dx.doi.org/10.21037/acs.2017.03.08 


\section{Introduction}

The heterogeneity of hypertrophic obstructive cardiomyopathy (HOCM) has stimulated great interest in its management. Various surgical strategies that aim to relieve left ventricular outflow tract obstruction (LVOTO) and correct mitral regurgitation (MR) caused by systolic anterior motion (SAM) of the anterior mitral valve (MV) leaflet have likewise evolved. Multifaceted approaches aiming to repair the MV and abolish SAM have been introduced by several surgeons, in addition to the fundamental septal myectomy. They include leaflet resection for an unsupported scallop of the posterior leaflet and artificial chordae or plication for an unsupported scallop of the anterior mitral leaflet (AML) with selective use of a flexible posterior annuloplasty band (1), complete resection and replacement of all AML chordae with the loop technique (2), radical debridement and repositioning of the papillary muscles (3), complete excision of secondary chordae of the AML (4), triangular resection of the anterior leaflet (5), AML extension with a pericardial patch $(6,7)$, sliding plasty of the posterior leaflet (8), edge-to-edge-technique $(1,9,10)$, or release of papillary muscles and plication of the AML (11).

Over the past 24 years, our institution has focused on the SAM of the MV as a significant component of HOCM. This article reports our complete experience with anterior mitral leaflet retention plasty (ALRP) in combination with septal myectomy.

\section{Methods}

The Institutional Review Board approved this retrospective study and waived the need for patient consent.

\section{Patients}

Between August 1986 and April 2014, 320 endomyocardial resections (muscle resection for midventricular obstruction through left ventricular apex, $n=4$ ) and 316 septal myectomies (muscle resection for LVOTO through aortotomy, including nine repeat septal myectomies and six septal myectomies post-alcohol septal ablation) were performed on 305 patients in our institution. Among these, 57 patients (mean age $38 \pm 2.5$ years, range 3 months -79.6 years), without previous alcohol septal ablation underwent primary surgery for HOCM - septal myectomy and ALRP directed to obviate the SAM phenomenon. The diagnosis of HOCM was based on clinical evaluation and echocardiography. Indications

\begin{tabular}{|c|c|}
\hline Characteristics & $\mathrm{N}(\%)$ \\
\hline $\begin{array}{l}\text { Mean age at surgery, } \pm \mathrm{SD} \\
\text { (median, range), years }\end{array}$ & $38 \pm 2.5(16.2,0.34-79.8)$ \\
\hline Sex (male/female) & $18 / 39$ \\
\hline \multicolumn{2}{|l|}{ NYHA class } \\
\hline 1 & $7(12.2)$ \\
\hline$\|$ & $18(31.6)$ \\
\hline III & $15(26.3)$ \\
\hline IV & $17(29.8)$ \\
\hline \multicolumn{2}{|l|}{ Predominant symptoms } \\
\hline Dyspnea & $8(14.0)$ \\
\hline Angina & $13(22.8)$ \\
\hline Syncope & $26(45.6)$ \\
\hline Combined symptoms & $10(17.5)$ \\
\hline \multicolumn{2}{|l|}{ Medical therapy } \\
\hline Beta blocker & 14 (24.6) \\
\hline Calcium channel blocker & $18(31.6)$ \\
\hline Combination & $25(43.9)$ \\
\hline \multicolumn{2}{|l|}{ Associated cardiac disease } \\
\hline Ventricular septal defect & $1(1.8)$ \\
\hline Patent foramen ovale & $1(1.8)$ \\
\hline Aortic stenosis & $3(5.2)$ \\
\hline Aortic insufficiency & $1(1.8)$ \\
\hline \multicolumn{2}{|l|}{ Urgency of surgery } \\
\hline Elective & $56(98.2)$ \\
\hline Urgent & $1(1.8)$ \\
\hline
\end{tabular}

SD, standard deviation; NYHA, New York Heart Association.

for surgery included refractory symptoms despite optimal medical therapy, which consisted of B-blockers, calcium channel blockers, or both. Associated cardiac diseases included ventricular septal defect $(\mathrm{n}=1)$, patent foramen ovale $(\mathrm{n}=1)$, aortic valve stenosis $(\mathrm{n}=3)$ and aortic insufficiency $(\mathrm{n}=1)$. Twenty-five $(43.8 \%)$ patients had a history of ventricular arrhythmia. None of the patients had a history of previous surgery (Table 1).

At the time of surgery, seven (12.2\%) patients were in 


\begin{tabular}{|c|c|c|c|c|}
\hline \multicolumn{5}{|l|}{ Clinical data } \\
\hline NYHA class & $3.08 \pm 0.61$ & $1.08 \pm 0.6$ & $0.83 \pm 0.47$ & 0.001 \\
\hline Number of drugs & $1.25 \pm 0.3$ & $0.5 \pm 0.4$ & $0.48 \pm 0.4$ & 0.001 \\
\hline \multicolumn{5}{|l|}{ Echocardiographic data } \\
\hline Mean IVS (median, range), mm & $28.2 \pm 3.4(30,25-34)$ & $12.3 \pm 2.7(14,18-25)$ & $10.5 \pm 1.1(12,15-23)$ & 0.001 \\
\hline Mean LVPW thickness (median, range), mm & $23.25 \pm 3.1(25,20-27)$ & $15.4 \pm 2.2(16,11-19)$ & $10.2 \pm 1.4(11,10-21)$ & 0.001 \\
\hline $\begin{array}{l}\text { LVOT mean pressure gradient } \\
\text { (median, range), } \mathrm{mmHg}\end{array}$ & $98.98 \pm 26.2(90,60-160)$ & $16.4 \pm 10.5(11,8-28)$ & $8.59 \pm 4.1(10,0-10)$ & 0.001 \\
\hline
\end{tabular}

New York Heart Association class I, 18 (31.6\%) patients were in class II, 15 (26.3\%) were in class III, and 17 (29.8\%) were in class IV. Preoperative mean LVOT pressure gradient, mean septal thickness and mean left ventricular posterior wall thickness were $98.98 \pm 26.2$ (median 90, range 60-160) $\mathrm{mmHg}, 28.2 \pm 3.4$ (median 30, range 25-34) mm, and 23.25 \pm 3.1 (median 25, 20-27) mm, respectively. Preoperative transesophageal quantitative Doppler echocardiography with quantification of the regurgitation jet, calculation of regurgitant volume and fraction as well as assessment of systolic pulmonary vein flow pattern showed MR and SAM with a mean grade of $3.2 \pm 0.15$ and $3.0 \pm 0.61$, respectively (Table 2).

\section{Surgical technique}

We have previously published our technique of subaortic septal myectomy and anterior leaflet retention plasty (ALRP) in children $(12,13)$ as well as in adults (14).

Intraoperative transesophageal echocardiography (TEE) is performed after induction of general anesthesia. This manoeuvre pays particular attention to the cardiac anatomy, MV morphology and function, and thickness of the ventricular septum.

Cardiac exposure is performed through a median sternotomy. Direct intracardiac pressures are measured simultaneously in the left ventricle and aorta. If the left ventricular outflow tract (LVOT) gradient is low $(<30 \mathrm{mmHg})$ because of the effects of anesthesia, either isoproterenol is administered or premature ventricular contractions are induced to determine the maximal gradient. Standard cardiopulmonary bypass with moderate hypothermia $\left(28-32{ }^{\circ} \mathrm{C}\right)$ is used and the left heart is vented. During aortic occlusion, myocardial protection, especially important because of the severe ventricular hypertrophy, is given through a generous infusion of antegrade cold crystalloid cardioplegia, followed by additional doses administered selectively onto the right and left coronary ostia every 15-20 minutes. An oblique aortotomy is performed rightwards, down to the noncoronary sinus and towards the aortic annulus. The aortic valve is inspected and the subvalvular region is exposed (Figure 1A). Optimum visualization of the ventricular septum is facilitated by posterior displacement of the left ventricle. Aside from using Morrow technique, which uses two parallel longitudinal incisions in the septum, we create parallel incisions into the septum directly opposite the AML (Figure 1B). The resection of long blocks of septal myocardium from between the two incisions is started just below the aortic annulus of the right coronary sinus and the commissure between the right and the left coronary sinuses (Hetzer's technique, Figure 1C) (12). Importantly, the incision is continued apically beyond the point of mitralseptal contact, marked by a fibrous band (Figure 1D). This 

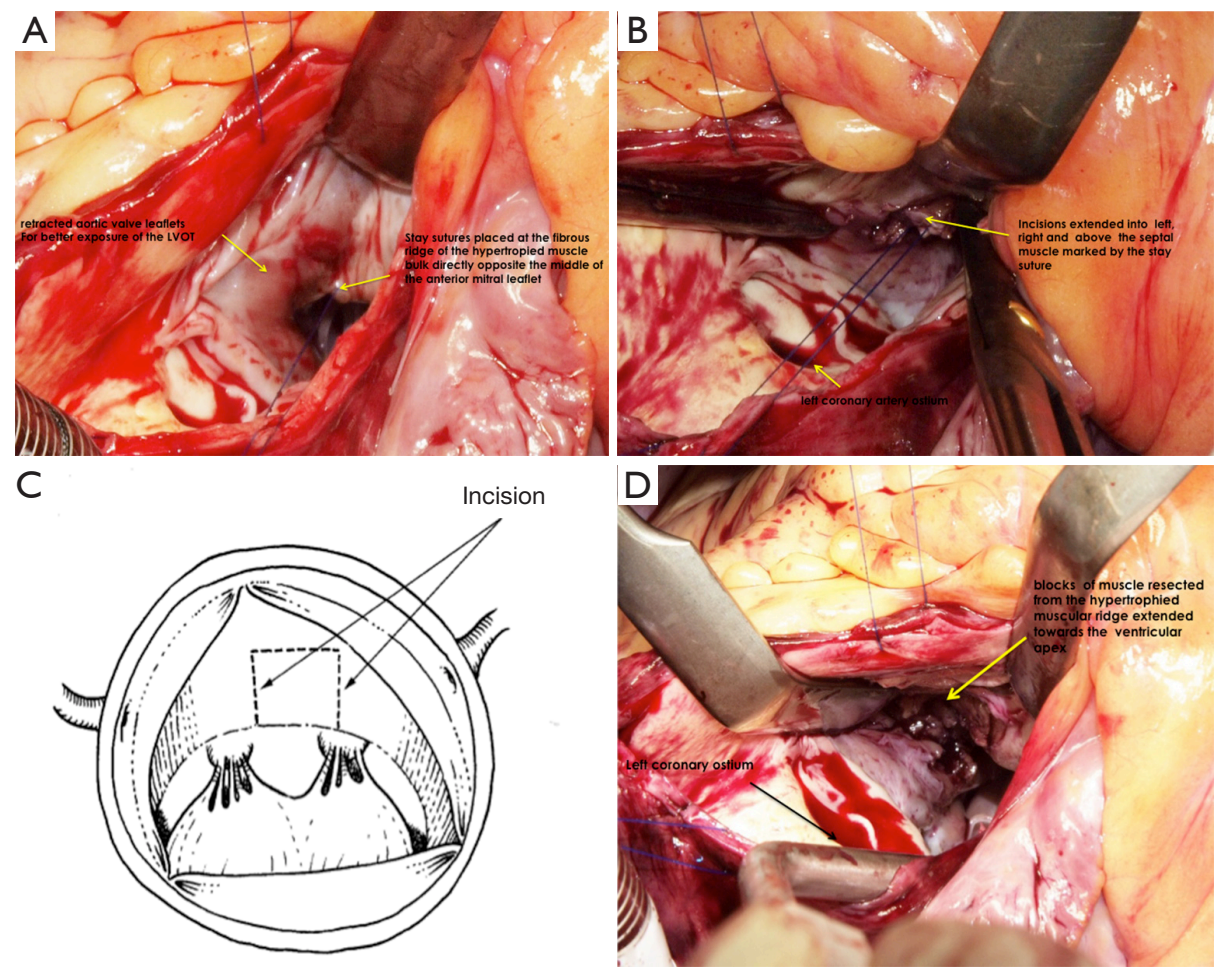

Figure 1 View through the aortotomy and aortic valve into the LVOT. (A) Stay suture placed at the fibrous ridge of the hypertrophied muscle bulk directly opposite the middle of the anterior mitral leaflet; (B) parallel incisions into the septum directly opposite the anterior mitral leaflet; (C) aortic view of septal myectomy opposite anterior mitral valve leaflet (dashed lines indicate myocardial septal incisions); (D) block of muscle resected from the hypertrophied muscular ridge extended towards the ventricular apex. LVOT, left ventricular outflow tract.

wide incision beneath the valve improves exposure of the important area toward the apex. Intraoperative pre-septal myectomy pressure gradient ranged from $40-105 \mathrm{mmHg}$ (mean $60 \pm 25 \mathrm{mmHg}$ ), and post-septal myectomy gradient ranged from $0-18 \mathrm{mmHg}$ (mean $5 \pm 6 \mathrm{mmHg}$ ).

This surgical technique particularly emphasises the importance of intraoperative TEE, performed after induction of general anesthesia, to assess the cardiac anatomy, ventricular septal wall thickness, morphology and function of the MV and its subvalvular apparatus, and the presence and severity of SAM. Likewise, simultaneous direct measurement of intracardiac pressures in the left ventricle and aorta serves as a practical guide to determining the maximal LVOT gradient.

\section{ALRP}

Direct exposure of the MV is facilitated through a left atriotomy along the interatrial groove. The morphology and mobility of the anterior MV leaflets and the subvalvular apparatus are carefully assessed. Thereafter, the segments of anterior MV leaflet closest to the trigones are sutured to the corresponding posterior annulus, wherein the polypropylene mattress sutures are pledgeted with untreated autologous pericardium. (Figure 2A) These sutures are passed through the coaptation line of the anterior leaflet and the corresponding posterior annulus trigones (Figure 2B) (12). MV opening is routinely measured to avoid mitral stenosis. The valve orifice area is assessed with a valve sizer (Figure 2C), and the appropriate valve size is determined based on the body surface area, according to the nomogram published by Rowlatt and colleagues (15). Saline injection through the valves and intraoperative TEE are routinely performed to assess the adequacy of repair (Figure 2D,E).

With respect to the technique of ALRP, passing the sutures through the coaptation line of the anterior leaflet and the corresponding opposite posterior annulus (Figure $3 A, B$ ) limits the mobility of the anterior MV leaflet in the segment running along the anterior annulus, which is then unable to produce SAM (Figure $4 A, B)$ (12). 

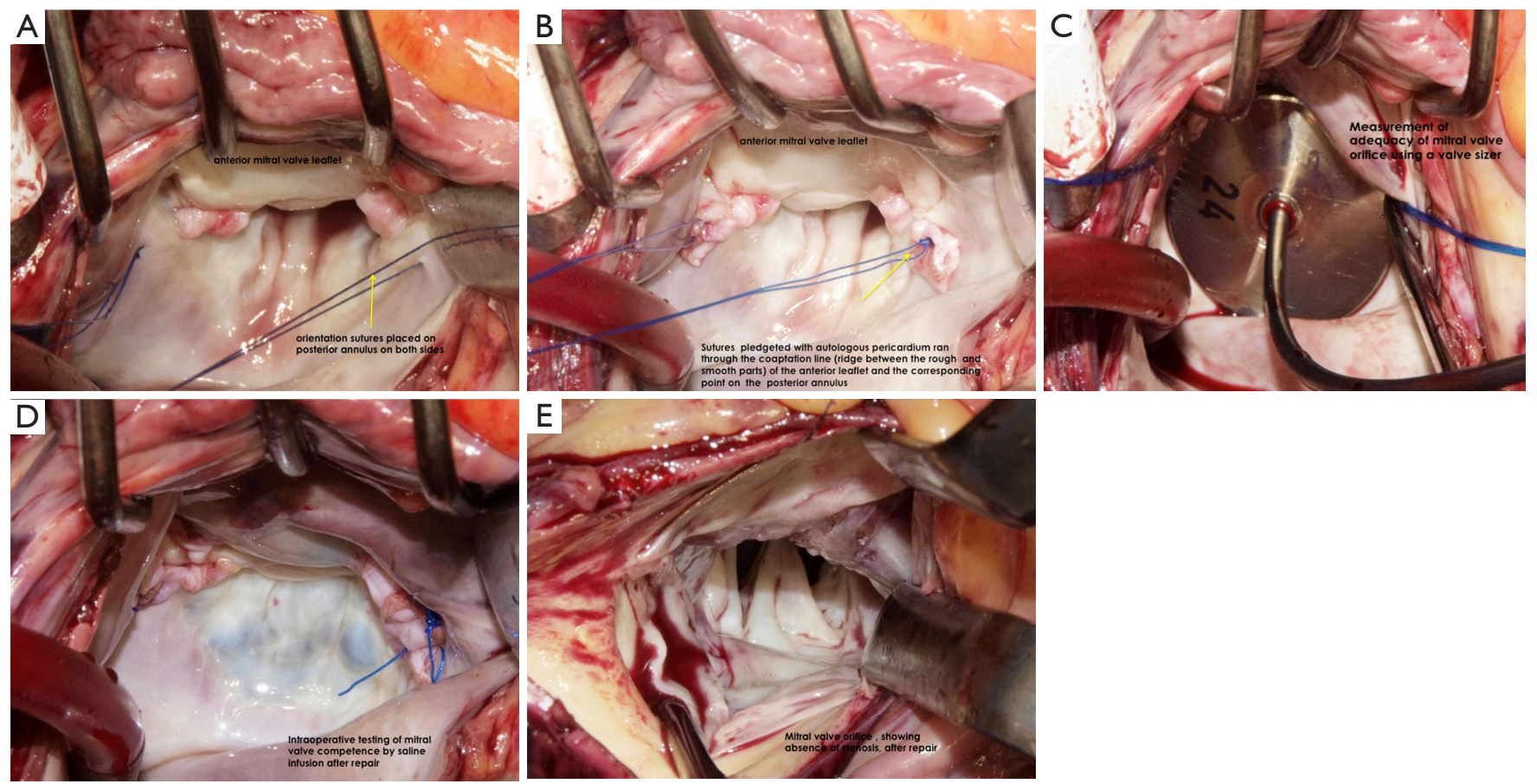

Figure 2 Atrial view of anterior leaflet retention plasty technique. (A) Orientation sutures placed on posterior annulus on both sides; (B) sutures pledgeted with autologous pericardium running through the coaptation line (ridge between the rough and smooth portions) of the anterior leaflet and the corresponding point on the posterior annulus; (C) measurement of adequacy of mitral valve orifice using a standard valve sizer; (D) intraoperative testing of mitral valve competence by saline infusion after repair; (E) mitral valve orifice , showing absence of stenosis, after repair.
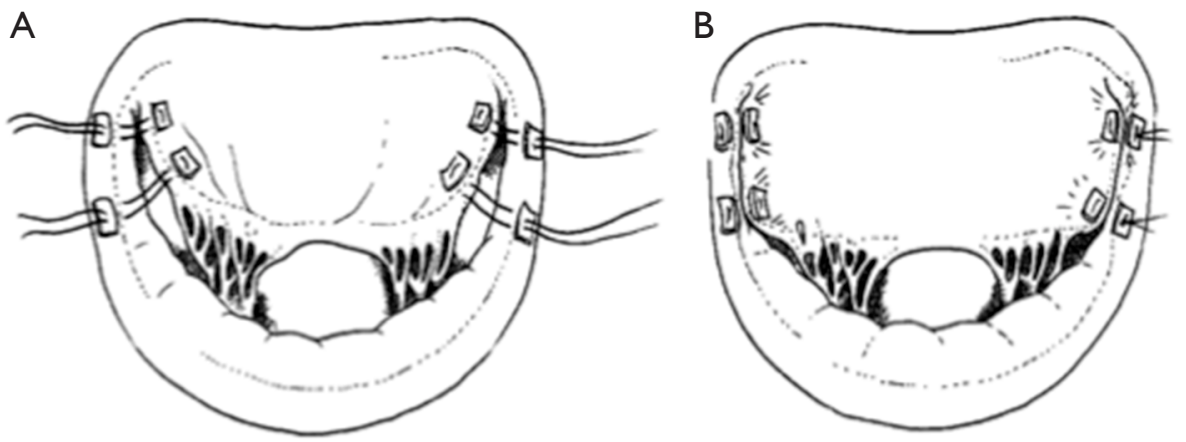

Figure 3 Graphic illustration. (A) Anterior leaflet retention plasty (ALRP) to correct systolic anterior motion (SAM); (B) atrial view of completed repair.

In these series, laxity of the anterior MV leaflets was present, but no distinct abnormalities of the chordae tendineae and papillary muscles were apparent. This repair was routinely guided by intraoperative TEE with particular attention to the septal anatomy and thickness, and MV function, mobility as well as anatomy of the subvalvular apparatus.
After the septal myectomy and ALRP, the aortic and MVs are routinely inspected to ensure that they have not been injured. Immediately after weaning the patient off cardiopulmonary bypass, pressures are remeasured in the left ventricle and aorta, and TEE evaluation is repeated, with special attention to the width of the interventricular septum, residual LVOT gradient, MV regurgitation and 

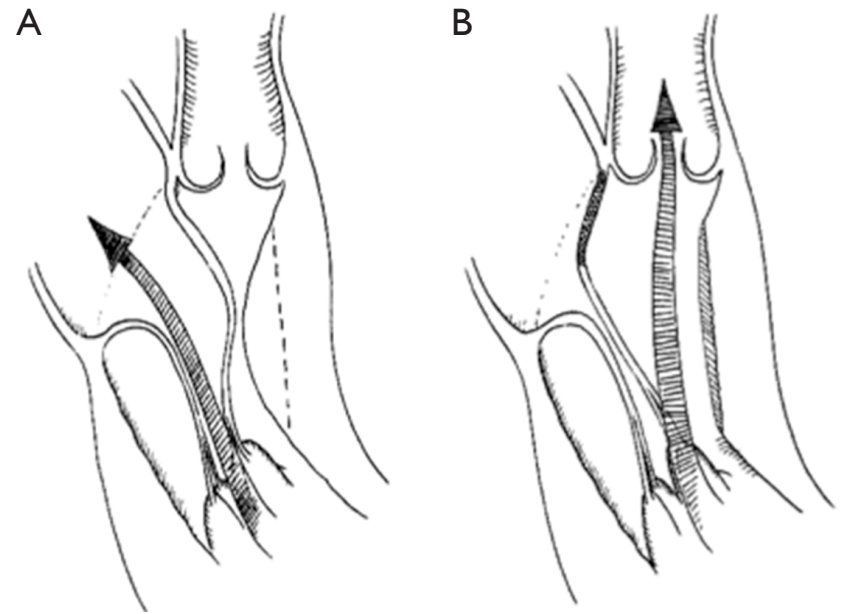

Figure 4 Graphic illustration. (A) Mitral insufficiency in HOCM and SAM before repair; (B) the redirection of mitral insufficiency following septal myectomy and ALRP. HOCM, hypertrophic obstructive cardiomyopathy; SAM, systolic anterior motion; ALRP, anterior leaflet retention plasty.

SAM. If myectomy has been successful, there will be little or no residual gradient, and little or no SAM of the MV. In general, we would resume cardiopulmonary bypass for reresection, if the gradient was greater than $15-20 \mathrm{mmHg}$.

Post-myectomy MR was reduced to a regurgitant fraction of 0 to $10 \%$. Postoperative transthoracic echocardiography was carried out annually, or if clinically indicated on the basis of symptoms. The degree of MV regurgitation was estimated by means of standard echocardiographic measurement techniques.

In 25 patients, permanent pacemakers were implanted with leads placed in the right atrium and the right ventricular apex with a shortened $A V$ interval of $<80 \mathrm{msec}$, to revert conduction sequence in the ventricle.

Operative data of 57 patients with HOCM who underwent septal myectomy and ALRP are shown in Table 3.

\section{Follow-up}

All patients operated on between 1990 and 2014 had complete follow-up with serial echocardiograms provided by the Department of Clinical Studies, Deutsches Herzzentrum Berlin and written correspondence from the referring physicians, and/or telephone interviews with patients or families. Transthoracic echocardiography was carried out annually or, if clinically indicated, on the basis of

\begin{tabular}{|c|c|}
\hline Operative variables & Values, mean (median, range) \\
\hline Bypass time, min & $111.84 \pm 48.25(111,54-267)$ \\
\hline Ischemia time, $\min$ & $62.67 \pm 23.01(57,18-118)$ \\
\hline Reperfusion time, min & $36.5 \pm 15.28(36,13-70)$ \\
\hline Total operative time, min & $229.69 \pm 78.79(195,120-415)$ \\
\hline Blood transfusion (n) & 10 \\
\hline
\end{tabular}

symptoms. The degree of $M V$ regurgitation was estimated using standard echocardiographic measurement techniques. The end of the follow-up study was April 2014.

\section{Statistical analysis}

All data were analyzed using the SPSS 16.0 (SPSS Inc., Chicago, IL, USA) software program. The data were expressed as absolute and percentage frequency values, and continuous data as mean \pm standard deviation as appropriate. Paired $t$-tests were used to compare categorical variables. A $\mathrm{P}$ value of 0.05 or less was considered significant. Freedom from reoperation and survival rates was analyzed via Kaplan-Meier estimates with 95\% confidence intervals (CI).

\section{Results}

Demographic profiles of the 57 patients are shown in Table 1. Fifty-six patients were operated upon on an elective basis. One patient had been resuscitated successfully after an out-of-hospital cardiac arrest and underwent urgent surgery. All underwent septal myectomy and ALRP, with concomitant VSD closure in one patient, closure of patent foramen ovale in another and aortic valve replacement in four patients. Mean cardiopulmonary bypass time was $111.84 \pm 48.25$ (median 111, range 54-267) minutes. Mean ischemic time was $62.67 \pm 23.01$ (median 57 , range 18-118) minutes (Table 3).

\section{Perioperative outcomes}

Preoperative, immediate postoperative, and the most recent follow-up echocardiographic data are presented in Table 2.

The mean follow-up period was $17.5 \pm 1.3$ years (median 


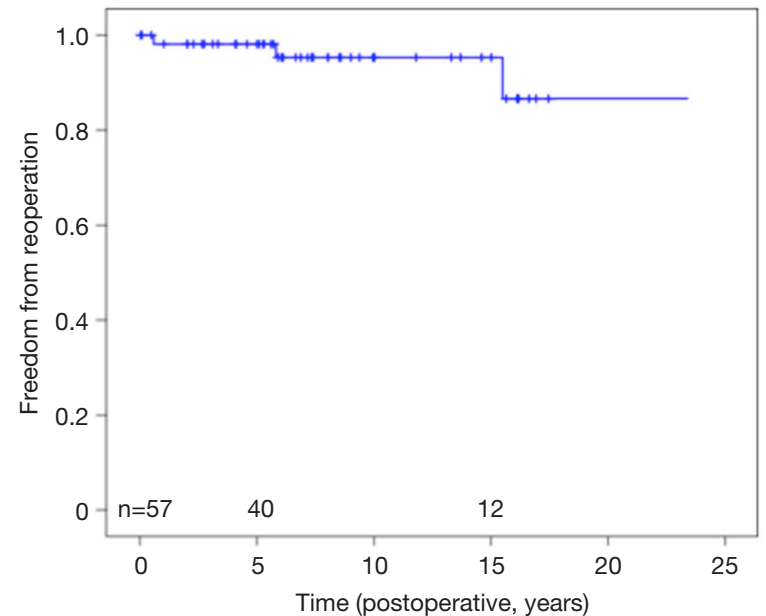

Figure 5 Freedom from repeat mitral valve intervention.

12, range 1-23.2 years). During follow-up, NYHA functional class improved from a preoperative mean of $3.08 \pm 0.61$ to a mean of $1.08 \pm 0.6$ postoperatively and $0.83 \pm 0.47$ in the latest follow-up, respectively $(\mathrm{P}=0.001)$.

Likewise, the number of maintenance drugs to relieve symptoms prescribed decreased significantly. Prior to surgery, the mean number of cardiac drugs used was $1.25 \pm 0.3$, whereas this number was significantly reduced to a mean of $0.5 \pm 0.4$ postoperatively and $0.48 \pm 0.4$ during follow-up, respectively $(\mathrm{P}=0.001)$.

Furthermore, we found a mean reduction in septal thickness, from a mean of $28.2 \pm 3.4 \mathrm{~mm}$ preoperatively to $12.3 \pm 2.7 \mathrm{~mm}$ after septal myectomy and $10.5 \pm 1.1 \mathrm{~mm}$ $(\mathrm{P}=0.001)$ during follow-up. Moreover, the LVOT pressure gradient significantly decreased from $98.98 \pm 26.2 \mathrm{mmHg}$ preoperatively to $16.4 \pm 10.5 \mathrm{mmHg}$ postoperatively and $8.59 \pm 4.1$ during follow-up $(\mathrm{P}=0.001)$. Mean posterior $\mathrm{LV}$ wall thickness and MR (trivial in $87 \%$ postoperatively) was also significantly reduced following surgery, and decreased further during follow-up period $(\mathrm{P}=0.001)$. The most significant finding is that SAM was non-existent immediately after surgery, and this finding was sustained during the latest follow-up.

\section{Reoperation}

Two patients underwent immediate MV replacements 24 hours postoperatively for severe residual MR. Another two patients underwent MV replacements 1 and 15 years after ALRP, for recurrent MR. Four received automatic implantable converter defibrillators during follow-up. Two

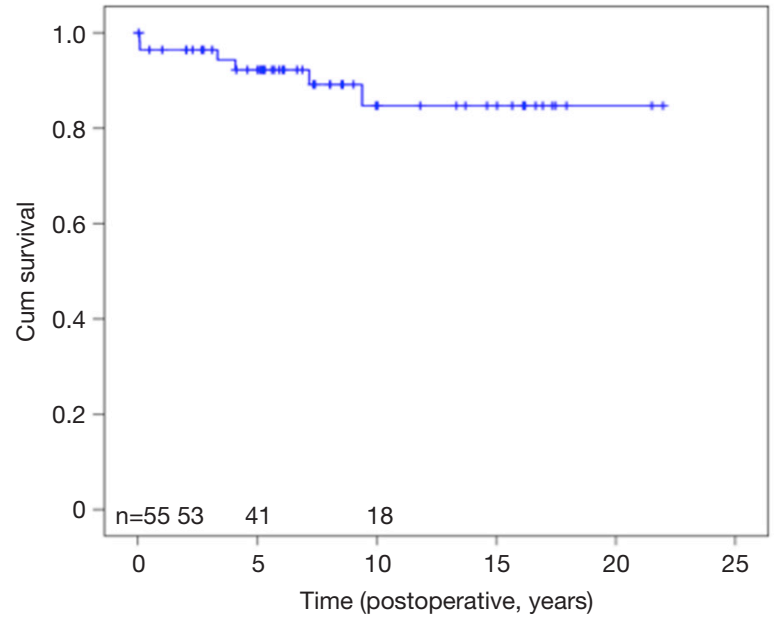

Figure 6 Cumulative survival.

patients underwent heart transplantation for heart failure 2 and 13 years postoperatively. One of the 25 patients with a permanent pacemaker underwent replacement of the pacemaker generator system 12 years after its implantation. Twenty-three-year freedom from repeat MV intervention was $92.9 \%$ (Figure 5 ).

\section{Survival}

Both heart transplant patients died from multiorgan failure, 2.1 and 15.2 years after transplantation. Three died of sudden cardiac death, 3.1, 6.6, and 11 years postoperatively. Twenty-year cumulative survival was $91.2 \%$ (Figure 6).

\section{Discussion}

Left ventricular outflow obstruction is present in $20 \%$ to $25 \%$ of patients with HOCM (16) and results primarily from septal hypertrophy. Its relief is facilitated by septal myotomy and myectomy (17) which has been an established and reliable surgical treatment. In children, however, transaortic septal myectomy may present special problems because of limited exposure through the aortic annulus. In this population, special care must be taken to avoid injury to the delicate and fragile aortic cusps during retraction for exposure of the hypertrophied septum (12). Too deep a resection may create a ventricular septal defect $(18,19)$ or even ventricular perforations. Likewise, the aortic valve is always at risk for injury from instruments passed through the valve and manipulated within the ventricle. Another special technical consideration relates to accurately judging 
the depth and length of the septal myectomy. Inadequate excision will leave residual LVOT obstruction and limit symptomatic improvement and/or survival. In this series, adequate myectomy was achieved in essentially all patients and careful hemodynamic assessment after weaning from the cardiopulmonary bypass is obligatory for optimal results. We do not hesitate to reinstitute cardiopulmonary bypass and consider resection of additional septal muscle if the residual systolic peak gradient exceeds $20 \mathrm{mmHg}$. In this series, there was an immediate $88 \%$ reduction in intraoperative LVOT gradient to a mean residual gradient of $16.4 \pm 10.5 \mathrm{mmHg}$ after septal myectomy. Complete heart block is another complication that may be produced by either traction against the aortic annulus or ventricular septum, or by placement of the initial septal incision too close to the membranous septum. In our later experience, we did not hesitate to implant permanent pacemakers with leads placed in the right atrium and ventricular apex with a shortened $\mathrm{AV}$ interval of $<80$ milliseconds, to revert conduction sequence in the ventricle, and this was done in 25 patients in this series.

Because of advances in understanding of the anatomical and physiological background of subaortic and interventricular obstruction, it has become apparent that, besides the myocardium, the anatomy of the MV apparatus frequently appears anomalous and may contribute to the obstructive component. Normally, the MV leaflets coaptate below the outflow tract as they are pulled posteriorly by the papillary muscles, where they do not impede the outward-directed blood flow. Factors that may disrupt this coaptation mechanism are valve elongation and anterior displacement of the papillary muscles, which predispose to SAM (20,21). Consequently, outflow tract obstruction and MR may persist after successful surgical myectomy. To counteract residual SAM, several authors (22-24) reported MV replacement as an alternative procedure in patients regarded as less suitable candidates for septal myectomy. In our institution, while we agree that the mitral valvular dysfunction is an integral factor in producing outflow obstruction, replacing the valve is not imperative either for reduction of the outflow gradient or for alleviation of mitral insufficiency. It is worth being realized that the severity of mitral insufficiency is related to the presence of SAM (24). Hence, it is essential to evaluate presence of abnormalities of the subvalvular apparatus in HOCM as well, since failure to recognize and treat them may be fatal or lead to incomplete relief of obstruction (25). Although absent in this series, the most important of these anomalies include anomalous papillary muscle insertion directly onto the AML, extensive fusion of papillary muscles with the ventricular septum or left ventricular free wall, abnormal chordae tendineae (false chords) that attach to the ventricular septum or free wall, and accessory papillary muscles, all of which may tether the mitral leaflets towards the septum and produce LVOT obstruction. This would inherently contraindicate performance of ALRP.

Our preferred approach, in addition to transaortic septal myectomy to address the LVOT obstruction is a concomitant ALRP performed through a left atriotomy. These combined procedures effectively abolished the LVOT obstruction, SAM, and mitral insufficiency. This approach is designed to avoid MV replacement, and hemodynamic results are encouraging. The selection criteria for ALRP included not only a relatively thick ventricular septum, presence of an abnormal MV apparatus, and prolapse of the anterior leaflet, but also persistent obstruction after myectomy. We address the prolapsing segment or unsupported anterior leaflet by avoiding the use of an annuloplasty ring. In patients with HOCM, the abnormal motion of the anterior MV leaflet in systole plays a key role in creating the outflow obstruction. The pull and push (Venturi) mechanism of the leaflets due to increased mitral leaflet length, laxity and anterior displacement of the papillary muscles allows the valve to protrude in the outflow tract (19). Accordingly, inward displacement of the papillary muscles towards each other results in chordal slack in the central leaflet portion and consequently SAM in the central portion of the valve (19). To counteract this, sutures are passed through the coaptation line of the anterior leaflet and the corresponding posterior annulus to decrease the length of the leaflet, resulting in horizontal retention which stretches and erects the chordae, thus enhancing leaflet coaptation (12).

Subsequently, the ALRP is effective in restricting the mobility of the anterior MV leaflet in the segment running along the anterior annulus, which is then unable to produce SAM and MR (Figure $3 A, B$ ). Furthermore, the normal anatomy of the MV is maximally restored.

Clinical and hemodynamic parameters including functional class, reduction of the LVOT gradient, and attenuation of MR and SAM after septal myectomy combined with ALRP showed sustained improvement during long-term follow-up. In all patients treated with this technique, SAM was virtually non-existent.

Limitations of the present study include the fact that we did not treat patients with previous operations. Also, 
we could not compare ALRP to the results with valve replacement because we generally perform MV repair, especially in those with HOCM.

\section{Conclusions}

Long-term follow up of HOCM patients who underwent simultaneous septal myectomy and ALRP showed sustained absence of SAM. There was absence of residual LVOT obstruction, and MR was reduced to trivial levels in the majority of patients. Corresponding improvements in hemodynamic and functional status were maintained at the latest follow-up.

\section{Acknowledgements}

We appreciate the assistance of Christine Detschades, Julia Stein, Carla Weber and Helge Haselbach.

\section{Footnote}

Conflicts of Interest: The authors have no conflicts of interest to declare.

\section{References}

1. Wan CK, Dearani JA, Sundt TM 3rd, et al. What is the best surgical treatment for obstructive hypertrophic cardiomyopathy and degenerative mitral regurgitation? Ann Thorac Surg 2009;88:727-31; discussion 731-2.

2. Seeburger J, Passage J, Borger MA, et al. A new concept for correction of systolic anterior motion and mitral valve regurgitation in patients with hypertrophic obstructive cardiomyopathy. J Thorac Cardiovasc Surg 2010;140:481-3.

3. Minakata K, Dearani JA, O'Leary PW, et al. Septal myectomy for obstructive hypertrophic cardiomyopathy in pediatric patients: early and late results. Ann Thorac Surg 2005;80:1424-9; discussion 1429-30.

4. Theodoro DA, Danielson GK, Feldt RH, et al. Hypertrophic obstructive cardiomyopathy in pediatric patients: results of surgical treatment. J Thorac Cardiovasc Surg 1996;112:1589-97; discussion 1597-9.

5. Grossi EA, Steinberg BM, LeBoutillier M 3rd, et al. Decreasing incidence of systolic anterior motion after mitral valve reconstruction. Circulation 1994;90:II195-7.

6. van der Lee C, ten Cate FJ, Geleijnse ML, et al. Percutaneous versus surgical treatment for patients with hypertrophic obstructive cardiomyopathy and enlarged anterior mitral valve leaflets. Circulation 2005;112:482-8.

7. Kofflard MJ, van Herwerden LA, Waldstein DJ, et al. Initial results of combined anterior mitral leaflet extension and myectomy in patients with obstructive hypertrophic cardiomyopathy. J Am Coll Cardiol 1996;28:197-202.

8. Jebara VA, Mihaileanu S, Acar C, et al. Left ventricular outflow tract obstruction after mitral valve repair. Results of the sliding leaflet technique. Circulation 1993;88:II30-4.

9. Mascagni R, Al Attar N, Lamarra M, et al. Edge-to-edge technique to treat post-mitral valve repair systolic anterior motion and left ventricular outflow tract obstruction. Ann Thorac Surg 2005;79:471-3; discussion 474.

10. Bhudia SK, McCarthy PM, Smedira NG, et al. Edgeto-edge (Alfieri) mitral repair: results in diverse clinical settings. Ann Thorac Surg 2004;77:1598-606.

11. Balaram SK, Ross RE, Sherrid MV, et al. Role of mitral valve plication in the surgical management of hypertrophic cardiomyopathy. Ann Thorac Surg 2012;94:1990-7; discussion 1997-8.

12. Delmo Walter EM, Siniawski H, Hetzer R. Sustained improvement after combined anterior mitral valve leaflet retention plasty and septal myectomy in preventing systolic anterior motion in hypertrophic obstructive cardiomyopathy in children. Eur J Cardiothorac Surg 2009;36:546-52.

13. Hetzer R, Delmo Walter EB, Hübler M, et al. Modified surgical techniques and long-term outcome of mitral valve reconstruction in 111 children. Ann Thorac Surg 2008;86:604-13.

14. Nasseri BA, Stamm C, Siniawski H, et al. Combined anterior mitral valve leaflet retention plasty and septal myectomy in patients with hypertrophic obstructive cardiomyopathy. Eur J Cardiothorac Surg 2011;40:1515-20.

15. Rowlatt U, Rimoldi H, Lev M. The quantitative anatomy of the normal child's heart. In: Gardner L. editor. Pediatric clinics of North America: Symposium on genetics. Philadelphia: WB Saunders, 1963:499-588.

16. Spirito P, Seidman CE, McKenna WJ, et al. The management of hypertrophic cardiomyopathy. $\mathrm{N} \mathrm{Engl} \mathrm{J}$ Med 1997;336:775-85.

17. Morrow AG. Hypertrophic subaortic stenosis. Operative methods utilized to relieve left ventricular outflow obstruction. J Thorac Cardiovasc Surg 1978;76:423-30.

18. Heric B, Lytle BW, Miller DP, et al. Surgical management of hypertrophic obstructive cardiomyopathy. Early and late results. J Thorac Cardiovasc Surg 1995;110:195-206; discussion 206-8. 
19. Robbins RC, Stinson EB. Long-term results of left ventricular myotomy and myectomy for obstructive hypertrophic cardiomyopathy. J Thorac Cardiovasc Surg 1996;111:586-94.

20. Levine RA, Vlahakes GJ, Lefebvre X, et al. Papillary muscle displacement causes systolic anterior motion of the mitral valve. Experimental validation and insights into the mechanism of subaortic obstruction. Circulation 1995;91:1189-95.

21. He S, Hopmeyer J, Lefebvre XP, et al. Importance of leaflet elongation in causing systolic anterior motion of the mitral valve. J Heart Valve Dis 1997;6:149-59.

22. Krajcer Z, Leachman RD, Cooley DA, et al. Septal myotomy-myomectomy versus mitral valve replacement in hypertrophic cardiomyopathy. Ten-year follow-up in 185 patients. Circulation 1989;80:157-64.

23. Walker WS, Reid KG, Cameron EW, et al. Comparison of ventricular septal surgery and mitral valve replacement for hypertrophic obstructive cardiomyopathy. Ann Thorac Surg 1989;48:528-34; discussion 535.

24. Minakata K, Dearani JA, Nishimura RA, et al. Extended septal myectomy for hypertrophic obstructive cardiomyopathy with anomalous mitral papillary muscles or chordae. J Thorac Cardiovasc Surg 2004;127:481-9.

25. McIntosh CL, Greenberg GJ, Maron BJ, et al. Clinical and hemodynamic results after mitral valve replacement in patients with obstructive hypertrophic cardiomyopathy. Ann Thorac Surg 1989;47:236-46.
Cite this article as: Delmo Walter EM, Javier MF, Hetzer R. Long-term outcome of simultaneous septal myectomy and anterior mitral leaflet retention plasty in hypertrophic obstructive cardiomyopathy: the Berlin experience. Ann Cardiothorac Surg 2017;6(4):343-352. doi: 10.21037/ acs.2017.03.08 